\title{
Quality assessment of environmental water by a simple and fast non-ionic hydrophobic natural deep eutectic solvent-based extraction procedure combined with liquid chromatography tandem mass spectrometry for the determination of plastic migrants
}

\author{
Álvaro Santana-Mayor ${ }^{1} \cdot$ Bárbara Socas-Rodríguez $^{2} \cdot$ Ruth Rodríguez-Ramos $^{1} \cdot$ Antonio V. Herrera-Herrera $^{3}$. \\ Miguel Ángel Rodríguez-Delgado ${ }^{1}$
}

Received: 17 November 2020 / Revised: 22 December 2020 / Accepted: 7 January 2021 / Published online: 3 February 2021

(C) Springer-Verlag GmbH Germany, part of Springer Nature 2021

\begin{abstract}
A non-ionic hydrophobic natural deep eutectic solvent (HNADES) based on thymol and menthol was proposed for the liquidliquid microextraction of fourteen phthalates and one adipate from environmental water samples. Separation, identification, and quantification were achieved by ultra-high-performance liquid chromatography coupled to tandem mass spectrometry. The main factors affecting the extraction efficiency were thoroughly studied. Sample $\mathrm{pH}$ of 8 and $100 \mu \mathrm{L}$ of thymol:menthol at molar ratio 2:1 were selected as the best conditions, while ionic strength and type of dispersant solvent were not relevant for the extraction of the target compounds. The whole methodology was validated for treated wastewater, runoff, and pond water matrices, using di- $n$ butyl phthalate-3,4,5,6- $\mathrm{d}_{4}$ and dihexyl phthalate-3,4,5,6- $\mathrm{d}_{4}$ as surrogates. Recovery ranged from 70 to $127 \%$ with relative standard deviation values lower than $14 \%$. Limits of quantification of the method were in the range $0.042-0.425 \mu \mathrm{g} / \mathrm{L} \mathrm{for} \mathrm{treated}$ wastewater, $0.015-0.386 \mu \mathrm{g} / \mathrm{L}$ for runoff, and $0.013-0.376 \mu \mathrm{g} / \mathrm{L}$ for pond water. The methodology was applied for the analysis of real treated wastewater, runoff, and pond water samples from different places of Tenerife and Gran Canaria (Canary Islands) finding the presence of diethyl phthalate, diallyl phthalate, dipropyl phthalate, benzylbutyl phthalate, di-n-butyl phthalate, bis-(2$n$-butoxyethyl) phthalate, di-n-pentyl phthalate, dicyclohexyl phthalate, and bis-(2-ethylhexyl) phthalate at concentrations between 105.2 and $3414 \mathrm{ng} / \mathrm{L}$.
\end{abstract}

Keywords Phthalic acid esters · Green solvent · Liquid-liquid microextraction · Water samples · Ultra-high-performance liquid chromatography $\cdot$ Mass spectrometry

Bárbara Socas-Rodríguez

barbara.socas@csic.es

Miguel Ángel Rodríguez-Delgado

mrguez@ull.edu.es

1 Departamento de Química, Unidad Departamental de Química Analítica, Facultad de Ciencias, Universidad de La Laguna (ULL), Avda. Astrofísico Fco. Sánchez, s/n, 38206 San Cristóbal de La Laguna, Spain

2 Laboratory of Foodomics, Institute of Food Science Research, CIAL, CSIC, Nicolás Cabrera 9, 28049 Madrid, Spain

3 Instituto Universitario de Bio-Orgánica Antonio González, Universidad de La Laguna (ULL), Avda. Astrofísico Fco. Sánchez, 2, 38206 San Cristóbal de La Laguna, Spain

\begin{tabular}{|c|c|}
\hline \multicolumn{2}{|l|}{ Abbreviations } \\
\hline$[\mathrm{BMIM}]\left[\mathrm{PF}_{6}\right]$ & $\begin{array}{l}1-\text { B u t y } 1-3-\text { m e th y li m i d a z o li u m } \\
\text { hexafluorophosphate }\end{array}$ \\
\hline$[\mathrm{OMIM}]\left[\mathrm{PF}_{6}\right]$ & $\begin{array}{l}1-\text { O c ty } 1-3-\text { m e th y li m i d a z o lium } \\
\text { hexafluorophosphate }\end{array}$ \\
\hline$[\mathrm{TBDP}]\left[\mathrm{BF}_{4}\right]$ & $\begin{array}{l}\text { Tributyldodecylphosphonium } \\
\text { tetrafluoroborate }\end{array}$ \\
\hline $\mathrm{AA}$ & Air-assisted \\
\hline $\mathrm{ACN}$ & Acetonitrile \\
\hline BBP & Benzyl butyl phthalate \\
\hline BPA & Bisphenol A \\
\hline $\mathrm{ChCl}$ & Choline chloride \\
\hline $\mathrm{DAD}$ & Diode-array detector \\
\hline DAP & Diallyl phthalate \\
\hline DBEP & Bis-(2-n-butoxyethyl) phthalate \\
\hline DBP & Di- $n$-butyl phthalate \\
\hline
\end{tabular}




\begin{tabular}{|c|c|}
\hline DBP-d $\mathrm{d}_{4}$ & Di- $n$-butyl phthalate-3,4,5,6- $\mathrm{d}_{4}$ \\
\hline DCHP & Dicyclohexyl phthalate \\
\hline DEEP & Bis-(2-ethoxyethyl) phthalate \\
\hline DEHA & Bis-(2-ethylhexyl) adipate \\
\hline DEHP & Bis-(2-ethylhexyl) phthalate \\
\hline DEP & Diethyl phthalate \\
\hline DES & Deep eutectic solvent \\
\hline DHP-d $\mathrm{d}_{4}$ & Dihexyl phthalate-3,4,5,6- $\mathrm{d}_{4}$ \\
\hline DINP & Diisononyl phthalate \\
\hline DLLME & Dispersive liquid-liquid microextraction \\
\hline DMEP & Bis-(2-methoxyethyl) phthalate \\
\hline DMP & Dimethyl phthalate \\
\hline DNOP & Di- $n$-octyl phthalate \\
\hline DNPP & Di- $n$-pentyl phthalate \\
\hline DPP & Dipropyl phthalate \\
\hline FID & Flame ionisation detector \\
\hline $\mathrm{GC}$ & Gas chromatography \\
\hline HDES & Hydrophobic deep eutectic solvent \\
\hline $\mathrm{HF}$ & Hollow fibre \\
\hline HNADES & Hydrophobic natural deep eutectic solvent \\
\hline HPLC & High-performance liquid chromatography \\
\hline IL & Ionic liquid \\
\hline $\mathrm{LC}$ & Liquid chromatography \\
\hline LLME & Liquid-liquid microextraction \\
\hline LOQ & Limit of quantification \\
\hline ME & Matrix effect \\
\hline MIP & Molecularly imprinted polymer \\
\hline MOF & Metal-organic framework \\
\hline MRM & Multiple reaction monitoring \\
\hline MS/MS & Tandem mass spectrometry \\
\hline MS & Mass spectrometry \\
\hline MWA & Microwave-assisted \\
\hline PAE & Phthalic acid ester \\
\hline RSD & Relative standard deviation \\
\hline SFOD & Solidified floating organic droplet \\
\hline $\mathrm{TC}$ & Temperature-controlled \\
\hline UHPLC & Ultra-high-performance \\
\hline & liquid chromatography \\
\hline US EPA & United States Environmental \\
\hline & Protection Agency \\
\hline UV & Ultraviolet detector \\
\hline VWD & Variable wavelength detector \\
\hline WH & World Health Organization \\
\hline
\end{tabular}

\section{Introduction}

The development of the plastic industry and the many benefits that plastic materials bring to the welfare of society have made them practically irreplaceable products. Its versatility, and unique properties, cost, and easy production have made plastic one of the most widely used materials nowadays. However, beyond the environmental pollution associated with the tons of plastics that are worldwide generated and not recycled, the additives that are added to plastic to obtain the desired properties also constitute an important concern in this sense, due to their known persistence. Their presence in the environment represents a real risk for living organisms and, in particular, for the health of human beings. Among the different families of additives, including flame retardants, antioxidants, and stabilisers, among others, phthalic acid esters (PAEs) are compounds widely used from the early twentieth century as plasticisers in the manufacture of plastic products. Since then, their use has spread to such an extent that the presence of these compounds in the environment is universal $[1,2]$.

Concentration of phthalates in the environment can vary from few nanograms per liter to hundreds of milligrams per liter which constitutes a clear over-exposition of the general population to these hazardous substances [2]. For this reason, several international organisations have established different regulations, lists, and guidelines, in which some PAEs with demonstrated endocrine disrupting activity have been included. Among them, the European Union have published regulations and guidelines referring to the Registration, Evaluation, Authorisation and Restriction of Chemicals in order to ensure environmental and human health protection [3] and quality standard of water policy [4], in which bis-(2-ethylhexyl) phthalate (DEHP), bis-(2methoxyethyl) phthalate (DMEP), benzyl butyl phthalate (BBP), di- $n$-butyl phthalate (DBP), di- $n$-pentyl phthalate (DNPP), and dicyclohexyl phthalate (DCHP) are classified as toxic substances for reproduction. The United States Environmental Protection Agency (US EPA) pointed out BBP, DBP, DCHP, and DEHP as high-priority substances [5], while dimethyl phthalate (DMP), diethyl phthalate (DEP), BBP, DBP, DEHP, and di-n-octyl phthalate (DNOP) were included in the 126 Priority Pollutants List [6], and BBP, DBP, DNPP, DEHP, DNOP, and diisononyl phthalate (DINP) in the US EPA Phthalates Action Plan due to their toxicity and environmental and human potential risk [7]. In addition, the same organisation [8] and the World Health Organization (WHO) [9] reported a regulation and a guideline about drinking water, in which reference values for bis-(2-ethylhexyl) adipate (DEHA) in the first case and DEHP in both cases were established. In this sense, it is intended that there are controls and restrictions for all those substances categorised as priority pollutants, among which are DEHP and DEHA that constitute an important environmental threat, in terms of toxicity to aquatic life and bioaccumulation in ecosystems, as well as damage to human health.

Several procedures have been applied for the extraction of PAEs from environmental matrices. In this regard, conventional techniques such as liquid-liquid extraction, solidliquid extraction, solid-phase extraction, and Soxhlet and alternative methodologies as liquid-phase microextraction in its 
different approaches, solid-phase microextraction, dispersive solid-phase extraction and its magnetic version, stir-bar sorptive extraction, supercritical fluid extraction, and pressurised solvent extraction, among others, combined with gas (GC) or liquid chromatography (LC) coupled to mass spectrometry (MS) have been the most commonly used [2]. Among them, liquid-liquid microextraction (LLME) procedures show the main advantages of dispersive liquid-liquid microextraction, such as simplicity, high preconcentration factors using extraction solvent volume in the order of microliter, rapidity, and low cost, but avoiding the use of disperser organic solvents [10]. Originally, toxic chlorinated solvents were used as extractants. However, with the advancement of material science, alternative solvents such as ionic liquids (ILs) and, more recently, deep eutectic solvents (DESs) have emerged. Particularly, DESs have arisen as the solvents of the twentyfirst century, with properties similar to ILs, but with higher biocompatibility and biodegradability, easier preparation, lower cost, and wider availability of raw materials [11]. Different classifications of DESs have been proposed, based on their components (types I-V) or their origin (composed by primary and secondary metabolites or not). However, most of them present high hydrophilicity hindering their applicability in aqueous media. In this regard, hydrophobic DESs (HDESs) have been presented as excellent alternative to overcome this issue. This kind of DESs can also be classified in two different categories: ionic HDES and non-ionic HDES. In the first group, long-chain tetraalkyl quaternary ammonium salts and long-chain alcohols or fatty acids are commonly used as HDES components, while in the second one, terpenes (menthol, thymol, and camphor), fatty acids (octanoic, decanoic, dodecanoic acids), or combination of them are the most tested [12]. In the case of PAE analysis, in most cases, hydrophilic DESs are employed. Thus, the use of HDESs represents a very significant improvement in terms of aqueous sample compatibility and procedure simplicity which also turns into lower cost of analysis. In addition, the selection of natural HDESs (HNADESs), based on the natural occurrence of their components, involves the development of more sustainable and safe procedures, avoiding additional contamination on the environmental media.

In this work, thymol:menthol HNADES-based LLME prior to ultra-high-performance liquid chromatography (UHPLC)-tandem mass spectrometry (MS/MS) was evaluated for the first time for the analysis of 14 PAEs and DEHA in environmental samples, including treated wastewater, runoff water, and pond water. In this sense, water samples destined to agricultural activities have been analysed considering the presence of phthalates in them as a consequence of human activities and, therefore, their potential harm to humans through the transport of these compounds between natural source water, soil, and crop products. To the best of our knowledge, this is the first work in which a thymol-based
HNADES has been used for the extraction of PAEs and DEHA.

\section{Experimental}

\section{Chemicals and materials}

Analytical standards of DMEP (CAS 117-82-8), diallyl phthalate (DAP; CAS 131-17-9), dipropyl phthalate (DPP; CAS 131-16-8), DBP (CAS 84-74-2), DCHP (CAS 84-617), DEHP (CAS 117-81-7), DNOP (CAS 117-84-0), DINP (CAS 20548-62-3), and DBP-3,4,5,6-d 4 (DBP-d d $_{4}$ CAS 93952-11-5) with purity higher than $97.0 \%$ (w/w) were supplied by Sigma-Aldrich Chemie (Madrid, Spain). DMP (CAS 131-11-3), bis-(2-ethoxyethyl) phthalate (DEEP; CAS 60554-9), DEP (CAS 84-66-2), BBP (CAS 85-68-7), bis-(2- $n$ butoxyethyl) phthalate (DBEP; CAS 117-83-9), DNPP (CAS 131-18-0), DEHA (CAS 103-23-1), and dihexyl phthalate-3,4,5,6-d $\mathrm{d}_{4}\left(\mathrm{DHP}-\mathrm{d}_{4}\right.$; CAS 1015854-55-3) with a purity higher than $97.0 \%(\mathrm{w} / \mathrm{w})$ were purchased from Dr. Ehrenstorfer GmbH (Augsburg, Germany).

Stock solutions, previously prepared in acetonitrile (ACN) of LC-MS grade at $100 \mathrm{mg} / \mathrm{L}$ for DMEP and DBP- $\mathrm{d}_{4}$; $500 \mathrm{mg} / \mathrm{L}$ for DEEP, DEP, DAP, DPP, BBP, DBP, DBEP, DNPP, DCHP, DEHA, and DNOP; and $1000 \mathrm{mg} / \mathrm{L}$ for DMP, DEHP, DINP, and DHP- $\mathrm{d}_{4}$, were used for the preparation of daily working mixtures of PAEs and DEHA by dilution. All solutions were stored in the darkness at $-18^{\circ} \mathrm{C}$.

All chemicals were of analytical reagent grade (except in those cases specifically indicated) and used as received. ACN and methanol of LC-MS grade and hydrochloric acid (25.0\%, w/w) were from Merck (Darmstadt, Germany). ( \pm )-Menthol $(99.8 \% \mathrm{w} / \mathrm{w})$, thymol $(99.5 \%, \mathrm{w} / \mathrm{w})$, sodium chloride $(\geq$ $99.5 \%, w / w)$, and hydroxide ( $\geq 98.0 \%$, w/w) were acquired from Sigma-Aldrich Chemie (Madrid, Spain). Deionised water was obtained from a Milli-Q system A10 (Millipore, MA, USA).

With the purpose of assuring the absence of phthalate contamination in the laboratory, a cleaning glass reagent (Godax Laboratories, MD, USA) was applied for volumetric glassware, while the rest of glassware was heated for $4 \mathrm{~h}$ at $550{ }^{\circ} \mathrm{C}$. Moreover, plastic material free of PAEs was used, and laboratory blanks were daily analysed to evaluate the possible presence of plastic migrants.

\section{Apparatus and software}

Fourier-Transform Infrared (FTIR) spectroscopy, Differential Scanning Calorimetry (DSC), and thermogravimetric analysis (TGA) were used to characterise the lab-made HNADESs and their individual components. FTIR spectra were obtained using a Cary 630 FTIR spectrometer (Agilent Technologies) 
equipped with a diamond attenuated total reflectance module and a $\mathrm{KBr}$ beam splitter. Spectra were recorded in the range $600-4500 \mathrm{~cm}^{-1}$, performing 256 scans of the background and samples with a resolution of $4 \mathrm{~cm}^{-1}$. DSC curves were recorded in a Discovery DSC 25 equipment (TA Instruments) with a Refrigerated Cooling System 90. Measures were made under inert atmosphere $\left(\mathrm{N}_{2}\right)$ at a flow rate of $50 \mathrm{~mL} / \mathrm{min}$ in a hermetic Tzero aluminium pan (TA Instruments). Heating cycles were made between -80 and $300{ }^{\circ} \mathrm{C}$ at a heating rate of $10{ }^{\circ} \mathrm{C} / \mathrm{min}$ for the HNADESs while -80 to $80{ }^{\circ} \mathrm{C}$ at $5{ }^{\circ} \mathrm{C} / \mathrm{min}$ was used for thymol and menthol. TGAs were carried out in a simultaneous thermal analyser Discovery SDT 650 (TA Instruments) in the range $25-300{ }^{\circ} \mathrm{C}$ at $10{ }^{\circ} \mathrm{C} / \mathrm{min}$. A hermetic Tzero aluminium pan and a $\mathrm{N}_{2}$ flow of $50 \mathrm{~mL} /$ min were used. All characterisation information and discussion can be found in the Supplementary Information (ESM; Characterisation of HNADESs Section and Figs. S1-S2).

Analyses of PAEs and DEHA were carried out in a Waters Acquity UPLC® H-Class, constituted of a sample manager with flow-through needle and a quaternary solvent from Waters Chromatography (Milford, MA, USA). The UHPLC system was coupled to an MS Xevo TQD (Waters Chromatography) using an electrospray ionisation interface in positive mode. Masslynx ${ }^{\text {TM }}$ software from Waters Chromatography was used to control the pumps and sample manager, as well as MS parameters and the collection and process of spectrum data. Separation was carried out in an Acquity $\mathrm{BEH} \mathrm{C}_{18}$ column $(50 \mathrm{~mm} \times 2.1 \mathrm{~mm}, 1.7 \mu \mathrm{m})$ using a pre-column with the same stationary phase $(5 \mathrm{~mm} \times 2.1 \mathrm{~mm}$, $1.7 \mu \mathrm{m})$, both from Waters Chromatography. Column and pre-column temperatures were settled at $40^{\circ} \mathrm{C}$.

The mobile phase was composed of $\mathrm{ACN}$ (solvent $\mathrm{A}$ ) and water (solvent B), both containing $0.1 \%(\mathrm{v} / \mathrm{v})$ of formic acid. Composition was established at 80/20 (v/v) A/B, at the beginning of the gradient. It was changed to $100 \% \mathrm{~A}(\mathrm{v} / \mathrm{v})$ in one min, which was held during $1 \mathrm{~min}$. Finally, the initial conditions were set up in $1 \mathrm{~min}$ and maintained during 2 min until system stabilisation. The flow rate was $0.3 \mathrm{~mL} / \mathrm{min}$ and the injection volume was $5 \mu \mathrm{L}$ at $10^{\circ} \mathrm{C}$.

The MS analysis was performed in multiple reaction monitoring (MRM) mode using the retention time and two different transitions as identification points. Besides, maximum tolerance of $\pm 20 \%$ for the relative intensity of the product and precursor ions was established [13]. Source conditions were applied as previously developed by Santana-Mayor et al. [14]. MRM transitions, cone voltages, and collision energies applied for each analyte are shown in Table S1 of the ESM.

\section{Samples selection}

Three different environmental water samples, treated wastewater, runoff water, and pond water, with $\mathrm{pH}$ values 8.40, 8.77 , and 8.69 at $25^{\circ} \mathrm{C}$, respectively, were selected as matrices to perform the validation of the method. Treated wastewater was obtained from a wastewater treatment plant in Tenerife (Canary Islands, Spain), equipped with ultrafiltration membrane bioreactor for biological wastewater treatment. Rainwater runoff was collected in the North of Tenerife and pond water in a metallic pond from the same island. All samples were previously filtered through a Durapore ${ }^{\circledR}$ PVDF membrane filter with $0.45-\mu \mathrm{m}$ pore size to remove solid particles.

Besides, 15 additional water samples were analysed to assess the occurrence of PAEs and DEHA in real samples. Five treated wastewaters were taken from treatment plants in Tenerife ( $\mathrm{pH}$ values ranging $7.52-8.16$ at $25^{\circ} \mathrm{C}$ ); three rainwater runoff samples and one from an underground gallery runoff ( $\mathrm{pH}$ between 7.72 and 7.98 at $25^{\circ} \mathrm{C}$ ) were collected at different locations of Tenerife (Canary Islands, Spain); and six pond water samples ( $\mathrm{pH}$ of $7.55-8.60$ at $25^{\circ} \mathrm{C}$ ) were collected from different ponds in Tenerife and Gran Canaria (Canary Islands, Spain).

Runoff and pond waters are used to irrigate agricultural crops and gardens, while treated wastewaters of reclaimed quality, after a process of ion removal to their high conductivity, could be used for the same purpose, especially in those places with water shortage issues [15]. In the Canary Islands, it is a common practice to store raining, underground, or even desalinated water in tanks to use them to irrigate different typical crops of the islands, such as banana plantations, avocado trees, and different tropical and sub-tropical fruits, or citrus fruits, among others $[16,17]$.

\section{Synthesis of HNADESs}

In this study, HDESs were prepared by mixing two natural secondary metabolites, thymol (as hydrogen bond donor) and menthol (as hydrogen bond acceptor), at molar ratios of 1:1, $1: 2$, and $2: 1$. For synthesis, the HDES components were placed in a glass vial and then stirred at $80^{\circ} \mathrm{C}$ for $10 \mathrm{~min}$ until a homogeneous liquid is formed [18]. The solvents were cooled to room temperature and stored in a vacuum desiccator to avoid the absorption of moisture.

\section{Liquid-liquid microextraction procedure}

The $\mathrm{pH}$ of $10 \mathrm{~mL}$ of spiked or non-spiked aqueous sample was adjusted to 8 , using $\mathrm{NaOH} 10 \mathrm{M}$ or $\mathrm{HCl}$ conc., and transferred into a $15-\mathrm{mL}$ glass centrifuge tube. Then, $100 \mu \mathrm{L}$ of HDES thymol:menthol 2:1 was added to the sample and vortexed for $1 \mathrm{~min}$. At this stage, a cloudy solution of microdroplets of HNADES was formed in the aqueous sample. Afterwards, it was centrifuged at $2465 \mathrm{~g}$ for $10 \mathrm{~min}$ at $15{ }^{\circ} \mathrm{C}$ in a $5810 \mathrm{R}$ centrifuge from Eppendorf (Hamburg, Germany) to achieve phase separation. Then, HNADES upper enriched-phase containing 
target analytes was collected, transferred into an injection vial, and 20-fold diluted with ACN. Next, $5 \mu \mathrm{L}$ was injected into the UHPLC-QqQ-MS/MS system. Due to the simplicity of the synthesis, as well as the low cost of raw materials and its good biocompatibility and biodegradability in aqueous systems [19-21], the extraction solvent was used only once to avoid possible carry-over problems, and the use of toxic solvents, involved in the cleaning procedure of HNADES.

\section{Results and discussion}

\section{UHPLC-QqQ-MS/MS method}

In this work, a group of 14 PAEs and one adipate were analysed using an Acquity $\mathrm{BEH} \mathrm{C}_{18}$ column. Based on the previous experience in the separation of this kind of compounds, different gradients consisted of $\mathrm{ACN} / \mathrm{H}_{2} \mathrm{O}$ (v/v) mixtures, both containing $0.1 \%(\mathrm{v} / \mathrm{v})$ of formic acid, were evaluated. In this case, the use of an HDES limits its application in reverse phase LC due to the need of high amount of organic mobile phase at the beginning of the gradient, which hampers the chromatographic performance. This issue was resolved increasing the initial percentage of $\mathrm{ACN}$ up to $80 \%(\mathrm{v} / \mathrm{v})$ and using the gradient described in the "Apparatus and software" section. Good separation was achieved with an analysis time below $3.5 \mathrm{~min}$.

\section{HNADES-LLME optimisation}

This work constitutes the first one in which PAEs and DEHA have been extracted from environmental samples using an HNADESs. Thus, prior to the validation and application of the methodology, an optimisation of those factors influencing the extraction efficiency, such as HNADES molar ratio and volume, as well as sample $\mathrm{pH}$ was developed. All experiments were performed in duplicate using Milli-Q water to avoid the possible influence of co-extracted matrix components. Hence, $10 \mathrm{~mL}$ of Milli-Q water spiked with the target analytes at a concentration of $100 \mu \mathrm{g} / \mathrm{L}$ of each compound was employed.

Other parameters such as ionic strength $(\mathrm{NaCl} 0-15 \%$, $\mathrm{w} / \mathrm{v}$ ) and the use of a dispersant solvent (ACN and methanol) were also evaluated. However, the obtained results showed that there are no significant improvements in efficiency or reproducibility of the extraction procedure when those were modified. Therefore, ionic strength was not modified and dispersant was not used, which reduce the use of additional toxic organic solvents, increasing the green character of the methodology.

\section{Selection of HNADES molar ratio}

The molar ratio thymol to menthol will play an important role in HNADES stability and physicochemical properties and, therefore, in its extraction capacity favouring or limiting the solubility of the target analytes in the solvent [22]. Hence, the extraction efficiencies of three different molar ratios of thymol:menthol HNADESs (i.e., 1:1, 1:2, and 2:1) were evaluated while the rest of conditions remained identical $(10 \mathrm{~mL}$ of Milli-Q water at pH 6 and $100 \mu \mathrm{L}$ of thymol:menthol HNADES). As can be seen in Fig. 1, molar ratio of 2:1 provided the best results for most of analytes, whereas decreasing the ratio of thymol produces a general decrease in the recovery values. This fact could be explained because an increase in the amount of thymol increases the number of hydrogen bond donors and, therefore, a greater number of interactions with the oxygenated groups of PAEs and DEHA [23]. Likewise, $\pi-\pi$ interactions between the aromatic rings of thymol and PAEs are favoured since its phenolic character could boost the solubility of PAEs, as aromatic compounds.

\section{Selection of sample pH}

The $\mathrm{pH}$ of sample solution can be a critical aspect in the transfer of organic compounds from the aqueous phase to the extraction organic phase [24]. Despite that PAEs and DEHA are not ionisable compounds (there is not $\mathrm{pKa}$ values established for these compounds), sample $\mathrm{pH}$ can influence the different interactions between analytes and HDES and, therefore, the extraction performance [25]. In this way, the effect of this parameter on the efficiency of the extraction was evaluated in the range $2-10$, maintaining the rest of parameters unchanged: $10 \mathrm{~mL}$ of Milli-Q water and $100 \mu \mathrm{L}$ of thymol:menthol 2:1, as extraction solvent. As can be seen in Fig. S3 (see ESM), no significant differences were found, except for DMP to which a decrease of the recovery was observed with $\mathrm{pH}$ increase. However, $\mathrm{pH} 8$ was established as the most suitable value since it presented lower relative standard deviation (RSD) values with recovery values around $100 \%$. In addition, it implied less modification of the initial conditions of sample and, therefore, a shorter preparation time.

\section{Selection of HNADES volume}

In LLME procedures, the volume of extraction solvent has a key role. The volume of extraction solvent delimits the amount of fine microdroplets formed, which is closely linked to the mass transfer of target analytes from the aqueous to the organic phase, and thus the extraction efficiency. Besides, it has an important effect on the preconcentration/dilution effect $[10,26]$. Thus, the volume of HNADES was evaluated in the range $50-150 \mu \mathrm{L}$ (every $25 \mu \mathrm{L}$ ). The results showed that 
Fig. 1 Effect of thymol:menthol HNADES composition on the extraction efficiency of the target analytes after the application of the LLME procedure. Extraction conditions: $10 \mathrm{~mL}$ of spiked Milli-Q water at $\mathrm{pH} 6$ and $100 \mu \mathrm{L}$ of thymol:menthol. Injected concentration of target analytes and surrogates: $100 \mu \mathrm{g} / \mathrm{L}$

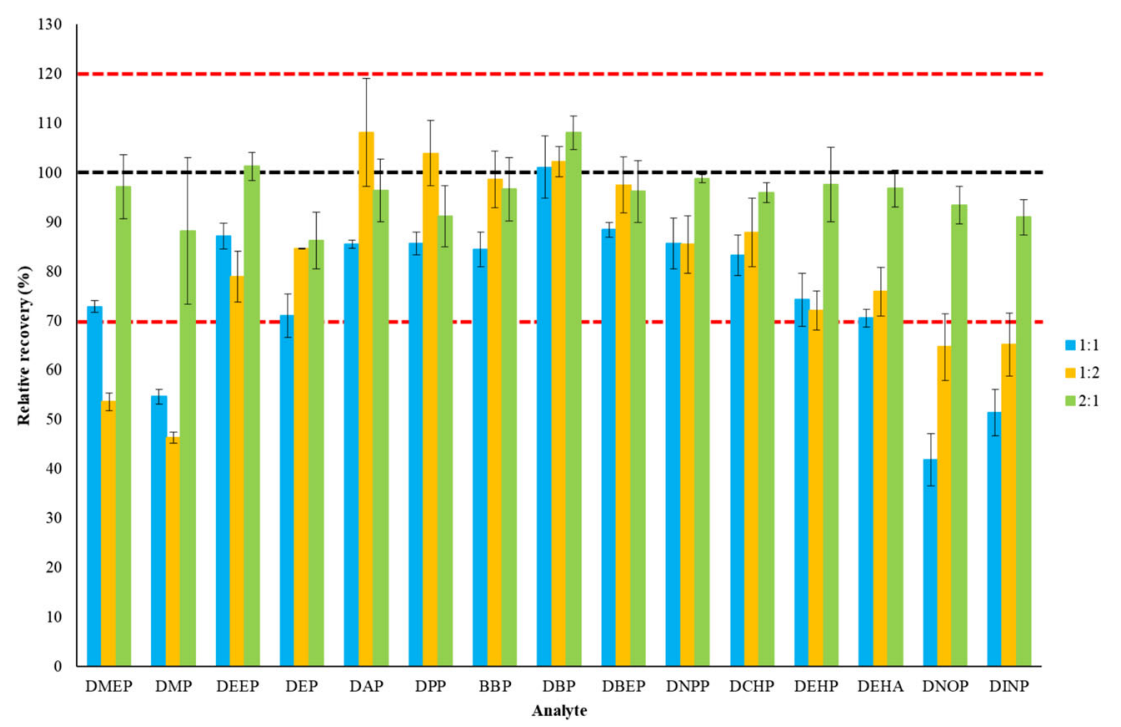

$100 \mu \mathrm{L}$ was found adequate to obtain an efficient extraction of the target analytes (see Fig. 2).

\section{LLME-UHPLC-QqQ-MS/MS validation}

The ubiquitous presence of phthalates in the laboratory environment as a consequence of the extended use of plastic materials, due to its low cost and versatility, is widely known. Even high-purity solvents, and separation and detection systems are important sources of contamination, giving rise to an important background signal that makes difficults the correct determination of these compounds [27]. Based on that, laboratory blanks of Milli-Q water were daily analysed to avoid obtaining biased results. Furthermore, blank samples were also analysed finding the presence of DEP, DBP, DEHP, and DEHA in all studied matrices. Consequently, to perform a fit for purpose validation, the peak areas of the analytes were subtracted when necessary.

Fig. 2 Effect of HNADES volume on the extraction efficiency of the target analytes after the application of the LLME procedure. Extraction conditions: $10 \mathrm{~mL}$ of spiked Milli-Q water at pH 8 and thymol:menthol 2:1. Injected concentration of target analytes and surrogates: $100 \mu \mathrm{g} / \mathrm{L}$
Considering that this work constitutes the first application of a HNADES for the extraction of PAEs and DEHA from environmental samples, a thorough validation of the procedure, in terms of matrix effect (ME), linearity, extraction efficiency, reproducibility, and sensitivity, was carried out. DBP$\mathrm{d}_{4}$ was used as surrogate for DMEP, DMP, DEEP, DEP, DAP, DPP, BBP, DBP, DBEP, DNPP, and DCHP, while DHP- $\mathrm{d}_{4}$ was applied for DEHP, DEHA, DNOP, and DINP, because of their similar behaviour to the compounds evaluated. With the aim of correcting the possible errors during the analytical procedure and improving the reproducibility of the method, surrogates were spiked at the beginning of the whole methodology [28].

Based on the influence of matrix components on the MS signal, by a suppression or enhancement effect [29], an ME study was performed at three concentration levels (low level: $2.5 \mu \mathrm{g} / \mathrm{L}$, intermediate level: $125.0 \mu \mathrm{g} / \mathrm{L}$, high level: $187.5 \mu \mathrm{g} / \mathrm{L}$ ), using the Matuszewski method [30]. In this 
way, five extractions were carried out by spiking each matrix at the indicated concentrations at the end of the extraction procedure. ME was calculated as the percentage of ratio areas between the spiked sample and a standard solvent at the same concentration level. As can be seen in Table S2 (see ESM), while DMEP, DMP, DPP, BBP, DBEP, and DEHP showed low or moderate signal suppression in one or more of matrices, low or moderate enhancement of the signal was observed for most of compounds, except for DEP and DAP in all types of samples and DEEP and DPP in runoff and pond which present high increase of the signal due to the possible competition between analytes and co-extracted matrix components during ionisation process [31-34].

Taking into account the widespread environmental presence of PAEs in the matrices evaluated and the results obtained from the ME study, matrix-matched calibration curves for each matrix were obtained by injecting seven different concentration levels $(n=7)$ in triplicate with the aim of studying the linearity of the developed methodology in the range of concentration of interest. As shown in Table S3 (see ESM), adequate $R^{2}$ values, higher than 0.9954 , were obtained for all phthalates and DEHA and matrices.

To assess the extraction efficiency of the methodology, a recovery study was developed for all samples comparing the peak areas obtained when matrices were spiked at three levels of concentration at the beginning and at end of the procedure (low level: $2.5 \mu \mathrm{g} / \mathrm{L}$, intermediate level: $125.0 \mu \mathrm{g} / \mathrm{L}$, high level: $187.5 \mu \mathrm{g} / \mathrm{L}$ ) by the extraction of five replicates at each level. As can be seen in Table 1, the obtained results showed a good efficiency and reproducibility of the extraction procedure, with relative recovery values in the range $74-118 \%$ for treated wastewater, $77-127 \%$ for runoff water, and $70-114 \%$ for pond water, and ruggedness with RSD values lower than $14 \%$ in all cases. Limits of quantification (LOQs) of the method, calculated as the lowest matrix-matched calibration concentration which provided a signal-to-noise ratio higher than 10 for the quantification transition and at least 3 for the confirmation transition, and taking into account the recovery of the method and the preconcentration/dilution factor, were also obtained. Values ranged between 0.042 and $0.425 \mu \mathrm{g} / \mathrm{L}$ for treated wastewater, between 0.015 and $0.386 \mu \mathrm{g} / \mathrm{L}$ for runoff water, and between 0.013 and $0.376 \mu \mathrm{g} / \mathrm{L}$ for pond water (see Table 1), which demonstrate the good sensitivity achieved with the developed HNADES-based LLME-UHPLC-QqQMS/MS method.

\section{Water quality assessment and occurrence of plastic migrants}

Once the whole methodology was successfully validated, a group of 18 real samples were analysed using the developed LLME-UHPLCQqQ-MS/MS method, with the aim of determining the concentration levels of the studied PAEs and
DEHA in environmental water samples from Tenerife and Gran Canaria: six treated wastewater samples (TWW1TWW6), five runoff waters (RW1-RW5), and seven pond water samples (PW1-PW7). As shown in Table 2, seven of the studied PAEs were found in some of the analysed samples (DEP, DAP, DPP BBP, DBP, DCHP, and DEHP). The presence of DEP, BBP, DBP, DCHP, and DEHP (see Fig. 3) is especially remarkable since the last four are included in the Appendix 6 of the Regulation No. 1907/2006 as toxic for reproduction (category 1B) [3]. In addition, DEP, BBP, DBP, and DEHP are also classified as toxic and Priority Pollutants under the Clean Water Act [6], as well as in the US EPA Phthalate Action Plan (BBP, DBP, and DNOP) due to their prevalence in the environment, widespread use, human exposure, and toxicity [7], and BBP, DBP, DCHP, and DEHP are designated as High-Priority Chemical Substances under the Toxic Substances Control Act [5], both of the US EPA.

Taking into account that in previously studies in which DESs were applied for the determination of PAEs in water samples only bottled and tap waters were analysed, the results obtained in this study were compared with others previously published, using other extraction procedures, in which similar matrices were evaluated. Regarding treated wastewater, a temporary dependence of the levels was found in these samples, which were taken in different time periods (November 2019, May 2020, June 2020, and July 2020). Considering the state of quarantine caused by the severe acute respiratory syndrome coronavirus 2 (SARS-CoV-2) pandemic, decreed in Spain in March 2020, and specifically in the Canary Islands, it seems that the concentrations found in the periods that included the quarantine time, the concentrations of PAEs dropped as a consequence of the decrease in human activity, such as tourism which represents the most important economic sector in the Canary Islands (TW2 and TW3). In the same way, the concentrations increase, reaching values close to $2700 \mathrm{ng} / \mathrm{L}$ for DBP as of mid-July 2020 (TWW5), which could be associated with an activity increase due to the return to work and leisure activities, as well as the opening of international means of transport.

The main mechanisms by which PAEs are eliminated using a membrane bioreactor in treated waters are adsorption and metabolic degradation processes, taking advantage of the retention of suspended solids and membrane (ultra)filtration to eliminate contaminants. However, depending on their molecular weight, they are easier to biodegrade or to absorb into suspended matter. Therefore, the procedure used in the purification plants could be crucial to reduce or eliminate PAEs from wastewater samples [35]. According to the last reports of the European Union, removals higher than $90 \%$ could be achieved in sewage treatment plants for BBP, DBP, and DEHP [36-38], although the bibliographic data shows different efficiency values depending on the treatment applied. 
Table 1 Results of the recovery study of the LLME-UHPLC-QqQ-MS/MS method for the selected compounds in water matrices at three levels of concentration

\begin{tabular}{|c|c|c|c|c|c|}
\hline \multirow[t]{2}{*}{ Analyte } & \multirow[t]{2}{*}{ Type of sample } & \multicolumn{3}{|l|}{ Relative recovery $\%$} & \multirow[t]{2}{*}{$\mathrm{LOQ}_{\text {method }}{ }^{\mathrm{d}}(\mu \mathrm{g} / \mathrm{L})$} \\
\hline & & Level $1^{\mathrm{a}}(n=5)(\mathrm{RSD}, \%)$ & Level $2^{\mathrm{b}}(n=5)(\mathrm{RSD}, \%)$ & Level $3^{\mathrm{c}}(n=5)(\mathrm{RSD}, \%)$ & \\
\hline \multirow[t]{3}{*}{ DMEP } & Treated wastewater & $101(10)$ & $101(10)$ & $105(8)$ & 0.044 \\
\hline & Runoff water & $100(12)$ & $101(11)$ & $105(4)$ & 0.017 \\
\hline & Pond water & $98(7)$ & $101(9)$ & $87(4)$ & 0.034 \\
\hline \multirow[t]{3}{*}{ DMP } & Treated wastewater & $88(8)$ & $92(10)$ & $92(8)$ & 0.203 \\
\hline & Runoff water & $88(10)$ & $90(11)$ & $83(3)$ & 0.049 \\
\hline & Pond water & $72(7)$ & $78(8)$ & $70(3)$ & 0.018 \\
\hline \multirow[t]{3}{*}{ DEEP } & Treated wastewater & $113(8)$ & $108(9)$ & $110(7)$ & 0.042 \\
\hline & Runoff water & $116(7)$ & $114(8)$ & $120(3)$ & 0.015 \\
\hline & Pond water & $108(8)$ & $114(9)$ & $96(4)$ & 0.030 \\
\hline \multirow{3}{*}{ DEP } & Treated wastewater & $113(12)$ & $104(9)$ & $106(6)$ & 0.044 \\
\hline & Runoff water & 77 (9) & $112(8)$ & $105(2)$ & 0.045 \\
\hline & Pond water & $79(7)$ & $96(7)$ & $84(3)$ & 0.074 \\
\hline \multirow[t]{3}{*}{ DAP } & Treated wastewater & $106(13)$ & $108(7)$ & $107(1)$ & 0.042 \\
\hline & Runoff water & $107(6)$ & $119(4)$ & $115(3)$ & 0.015 \\
\hline & Pond water & $97(6)$ & $99(4)$ & $88(3)$ & 0.014 \\
\hline \multirow[t]{3}{*}{ DPP } & Treated wastewater & $107(7)$ & $105(4)$ & $107(2)$ & 0.043 \\
\hline & Runoff water & $107(6)$ & $119(1)$ & $112(4)$ & 0.016 \\
\hline & Pond water & $98(4)$ & $98(3)$ & $88(2)$ & 0.014 \\
\hline \multirow[t]{3}{*}{ BBP } & Treated wastewater & $107(5)$ & $98(3)$ & $107(1)$ & 0.086 \\
\hline & Runoff water & $109(3)$ & $123(1)$ & $119(3)$ & 0.036 \\
\hline & Pond water & $101(2)$ & $100(3)$ & $92(3)$ & 0.013 \\
\hline \multirow[t]{3}{*}{ DBP } & Treated wastewater & $118(12)$ & $102(5)$ & $105(2)$ & 0.085 \\
\hline & Runoff water & $100(3)$ & $125(1)$ & $108(3)$ & 0.040 \\
\hline & Pond water & $77(9)$ & $93(3)$ & $88(2)$ & 0.376 \\
\hline \multirow[t]{3}{*}{ DBEP } & Treated wastewater & $112(5)$ & $101(3)$ & $106(1)$ & 0.425 \\
\hline & Runoff water & $116(2)$ & $125(1)$ & $125(3)$ & 0.072 \\
\hline & Pond water & $105(3)$ & $104(4)$ & $99(5)$ & 0.126 \\
\hline \multirow[t]{3}{*}{ DNPP } & Treated wastewater & $111(4)$ & $100(10)$ & $104(3)$ & 0.087 \\
\hline & Runoff water & $109(3)$ & $127(1)$ & $126(2)$ & 0.036 \\
\hline & Pond water & $104(3)$ & $100(4)$ & $95(3)$ & 0.033 \\
\hline \multirow[t]{3}{*}{ DCHP } & Treated wastewater & $110(7)$ & $98(4)$ & $103(2)$ & 0.088 \\
\hline & Runoff water & $100(3)$ & $124(1)$ & $123(1)$ & 0.038 \\
\hline & Pond water & $108(3)$ & $101(4)$ & $95(3)$ & 0.032 \\
\hline \multirow[t]{3}{*}{ DEHP } & Treated wastewater & $86(6)$ & $109(8)$ & $87(7)$ & 0.049 \\
\hline & Runoff water & $117(5)$ & $95(4)$ & $87(4)$ & 0.075 \\
\hline & Pond water & $73(5)$ & $80(5)$ & $85(6)$ & 0.074 \\
\hline \multirow[t]{3}{*}{ DEHA } & Treated wastewater & $75(6)$ & $109(10)$ & $89(11)$ & 0.051 \\
\hline & Runoff water & $110(6)$ & $99(7)$ & $97(3)$ & 0.073 \\
\hline & Pond water & $74(6)$ & $75(3)$ & $82(3)$ & 0.076 \\
\hline \multirow[t]{3}{*}{ DNOP } & Treated wastewater & $74(14)$ & $105(7)$ & $88(8)$ & 0.209 \\
\hline & Runoff water & $94(13)$ & $91(3)$ & $98(6)$ & 0.041 \\
\hline & Pond water & $104(8)$ & $87(8)$ & $84(3)$ & 0.064 \\
\hline \multirow[t]{3}{*}{ DINP } & Treated wastewater & $86(8)$ & $73(3)$ & $84(5)$ & 0.204 \\
\hline & Runoff water & $99(13)$ & $97(6)$ & $97(5)$ & 0.386 \\
\hline & Pond water & $97(8)$ & $86(10)$ & $80(3)$ & 0.135 \\
\hline
\end{tabular}

Concentration of the target analytes was ${ }^{\mathrm{a}} 2.5 \mu \mathrm{g} / \mathrm{L} ;{ }^{\mathrm{b}} 125.0 \mu \mathrm{g} / \mathrm{L} ;{ }^{\mathrm{c}} 187.5 \mu \mathrm{g} / \mathrm{L}$. ${ }^{\mathrm{d}}$ Defined as the lowest matrix-matched calibration concentration which provides a signal-to-noise ratio higher than 10 for the quantification transition and at least 3 for the confirmation transition taking into account the preconcentration/dilution factors as well as the recovery values of the method

These facts may explain that the concentrations found in the treated wastewater samples analysed were not as high as might be expected in this type of sample. If the results obtained are compared with other previously developed studies in which effluent samples were analysed, it can be corroborated that the concentrations found are far below. In this regard, Gao et al. [39] found DEP, DBP, BBP, and DEHP, among other PAEs, at concentrations ranging between 1.11 and $25.4 \mu \mathrm{g} / \mathrm{L}$, whereas the concentrations found in the samples analysed in this work were much lower $(0.120-3.414 \mu \mathrm{g} / \mathrm{L})$. Another example is the work carried out by Clara et al. [40], in which DEP, DBP, BBP, and DEHP were found at concentrations in the range $0.083-6.6 \mu \mathrm{g} / \mathrm{L}$. These values were very similar with those obtained by Gani et al. [41] in North India, who found DEP, DBP, BBP, and DEHP in 15 effluents at mean concentrations of 1.555 to $4.864 \mu \mathrm{g} / \mathrm{L}$. Al-Saleh et al. [42] analysed 114 samples of five wastewater treatment plants in three major Saudi cities. DEP, DBP, BBP, and DEHP were 
found at mean concentrations in the range $0.182-0.748 \mu \mathrm{g} / \mathrm{L}$. The values obtained are in the same range to the ones found in this work, in contrast with the studies of Clara and Gani, in which higher concentrations of the analytes were found.

Regarding the pond waters, the samples stored in plastic ponds, despite even being from different Islands (PW2 and PW6), showed the same trend, in which all the analytes detected are at very similar levels of concentrations (116.1-358.0 ng/ L), with the exception of DBP (1974.4 ng/L and $1035.8 \mathrm{ng} / \mathrm{L}$, respectively). In contrast, those samples from open-cement ponds (PW3 and PW5) presented very different concentrations of PAEs. This may be because one of them (PW3) is supplied with rainwater, while the other (PW5) is supplied with water by a Gran Canaria dam transported through PVC pipes over approximately $12 \mathrm{~km}$. It contained very high concentration levels of DEP and DBP. What does seem to stand out is that the first sample is the one with the highest concentration of DEHP (1083.0 ng/L), despite being stored on a pond made of cement. However, it can also be influenced to a greater extent by wind and rain and, therefore, by human activities and their waste. Likewise, it seems remarkable that the highest concentrations of DEP, not only in pond water but also in all the samples analysed, were found in a pond water sample from an opencement pond (PW5), and a pond water sample from a polyester fibre glass tank (PW7) (1536.5 ng/L and $1539.6 \mathrm{ng} / \mathrm{L}$, respectively), both from the island of Gran Canaria. Another important aspect is the fact that DAP is presented in three pond water samples (PW2, PW5, and PW7). This could be related to one of the tanks which is made of plastic, the other is supplied through PVC pipes, and the last one is made of fibreglassreinforced polyester.

If data obtained from pond water analysis are compared with previous one, DBP has been found in other works in a wide range of concentrations (0.226-112.4 $\mu \mathrm{g} / \mathrm{L})$ [14, 43-45]. DEP was found by He et al. [43] at $0.25 \mu \mathrm{g} / \mathrm{L}$, while DPP and BBP were found by Santana-Mayor et al. [14] at concentrations of $35 \mathrm{ng} / \mathrm{L}$ and $16 \mathrm{ng} / \mathrm{L}$, respectively. These values are lower than those obtained in the present study. Only the work carried out by Ye et al. [44] quantified DEHP at a concentration of $31.2 \mu \mathrm{g} / \mathrm{L}$, which is a much higher value than the reference values and the indications of the different international organisations.

Regarding runoff water samples, only DBP, at concentrations between 105.2 and $1156.7 \mathrm{ng} / \mathrm{L}$, and DEHP in the runoff water sample stored in a plastic tank $(142.0 \mathrm{ng} / \mathrm{L})$ were quantified. Likewise, DEP, BBP, and DCHP were found in some of them at concentrations below the LOQs of the method (45 ng/L, $36 \mathrm{ng} / \mathrm{L}$, and $38 \mathrm{ng} / \mathrm{L}$, respectively). These values agree with those previously obtained by Rodríguez-Ramos et al. [46], in which samples of agricultural soils from crop

Table 2 Results of the analysis of different environmental water samples using the developed LLME-UHPLC-QqQ-MS/MS method

\begin{tabular}{|c|c|c|c|c|c|c|c|}
\hline \multirow[t]{2}{*}{ Sample } & \multicolumn{7}{|c|}{ Analyte concentration \pm confidence interval $(\mathrm{ng} / \mathrm{L})^{\mathrm{a}}$} \\
\hline & DEP & DAP & DPP & BBP & DBP & DCHP & DEHP \\
\hline TWW1 & $122.6 \pm 0.8$ & n.d. & n.d. & n.d. & $619.9 \pm 0.4$ & n.d. & $<\mathrm{LOQ}$ \\
\hline TWW2 & $<\mathrm{LOQ}$ & n.d. & n.d. & n.d. & $<$ LOQ & n.d. & $<\mathrm{LOQ}$ \\
\hline TWW3 & $<\mathrm{LOQ}$ & n.d. & n.d. & n.d. & $<\mathrm{LOQ}$ & n.d. & $<\mathrm{LOQ}$ \\
\hline TWW4 & $130.1 \pm 0.8$ & n.d. & n.d. & $<$ LOQ & $674.9 \pm 0.4$ & $<$ LOQ & $<\mathrm{LOQ}$ \\
\hline TWW5 & $387.1 \pm 0.7$ & n.d. & n.d. & n.d. & $2692.4 \pm 0.4$ & n.d. & $<\mathrm{LOQ}$ \\
\hline TWW6 & $127.1 \pm 0.8$ & n.d. & n.d. & n.d. & $<\mathrm{LOQ}$ & $<$ LOQ & $3414 \pm 1$ \\
\hline RW1 & $<\mathrm{LOQ}$ & n.d. & n.d. & n.d. & $<\mathrm{LOQ}$ & $<\mathrm{LOQ}$ & $<\mathrm{LOQ}$ \\
\hline RW2 & $<\mathrm{LOQ}$ & n.d. & n.d. & n.d. & $105.2 \pm 0.3$ & $<\mathrm{LOQ}$ & $<\mathrm{LOQ}$ \\
\hline RW3 & $<\mathrm{LOQ}$ & n.d. & n.d. & $<\mathrm{LOQ}$ & $1156.7 \pm 0.3$ & $<\mathrm{LOQ}$ & $<\mathrm{LOQ}$ \\
\hline RW4 & $<\mathrm{LOQ}$ & n.d. & n.d. & n.d. & $938.1 \pm 0.3$ & n.d. & $<\mathrm{LOQ}$ \\
\hline RW5 & $<\mathrm{LOQ}$ & n.d. & n.d. & $<$ LOQ & $304.6 \pm 0.3$ & $<$ LOQ & $142.0 \pm 0.7$ \\
\hline PW1 & $<\mathrm{LOQ}$ & n.d. & n.d. & $<\mathrm{LOQ}$ & $811.7 \pm 0.3$ & $207.4 \pm 0.4$ & $229.6 \pm 0.6$ \\
\hline PW2 & $263.9 \pm 0.7$ & $152.6 \pm 0.3$ & $143.0 \pm 0.5$ & $116.1 \pm 0.4$ & $1974.4 \pm 0.3$ & $211.2 \pm 0.4$ & $<\mathrm{LOQ}$ \\
\hline PW3 & $<\mathrm{LOQ}$ & n.d. & n.d. & n.d. & n.d. & n.d. & $1083.0 \pm 0.6$ \\
\hline PW4 & $177.6 \pm 0.8$ & n.d. & n.d. & n.d. & $1227.7 \pm 0.3$ & $211.3 \pm 0.4$ & $<\mathrm{LOQ}$ \\
\hline PW5 & $1536.5 \pm 0.7$ & $151.1 \pm 0.3$ & n.d. & $<\mathrm{LOQ}$ & $1736.2 \pm 0.3$ & $206.4 \pm 0.4$ & $<\mathrm{LOQ}$ \\
\hline PW6 & $358.0 \pm 0.7$ & n.d. & n.d. & $120.0 \pm 0.4$ & $1035.8 \pm 0.3$ & $215.4 \pm 0.4$ & $<\mathrm{LOQ}$ \\
\hline PW7 & $1539.6 \pm 0.7$ & $153.8 \pm 0.3$ & n.d. & $111.0 \pm 0.4$ & $660.6 \pm 0.3$ & $213.9 \pm 0.4$ & $<$ LOQ \\
\hline
\end{tabular}

n.d., not detected. TWW1-TWW6: treated wastewater samples. RW1, RW3-5: rainwater runoff samples; RW2: underground gallery runoff sample. PW1: metallic tank pond water sample; PW2 and PW6: plastic tank pond water samples; PW3 and PW5: open-cement tank pond water samples; PW4: close-cement tank pond water sample. ${ }^{\text {a }}$ Results obtained as an average of three analyses for each sample 


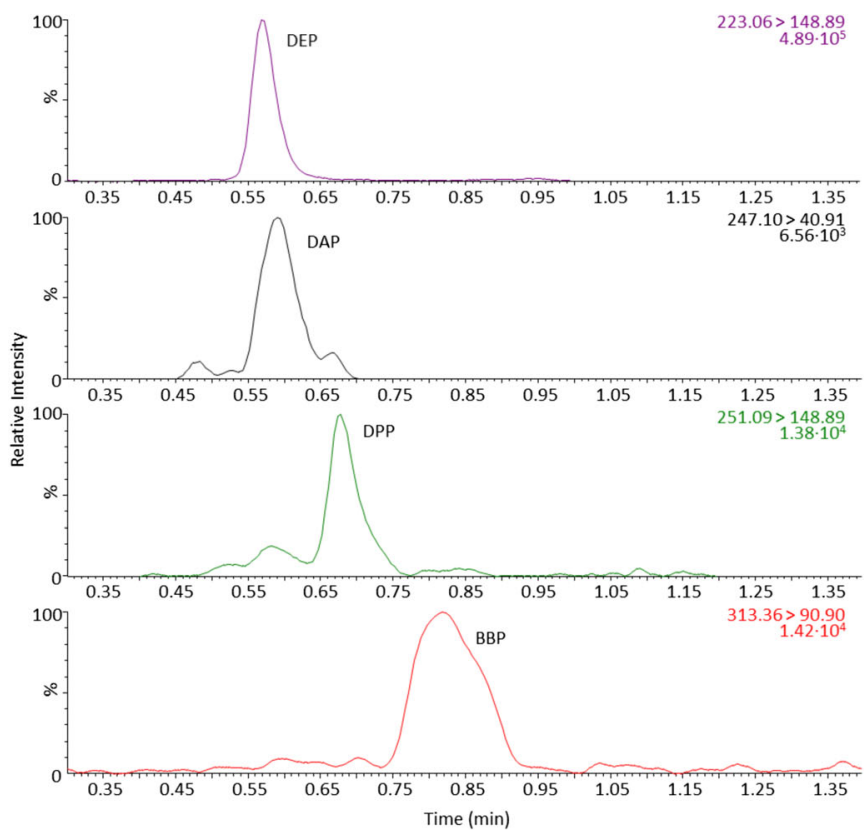

Fig. 3 UHPLC-QqQ-MS/MS chromatograms of PAEs found in a pond water sample stored in a plastic tank (PW2). Concentration of analytes: $263.9 \pm 0.7 \mathrm{ng} / \mathrm{L}$ for DEP, $152.6 \pm 0.3 \mathrm{ng} / \mathrm{L}$ for DAP, $143.0 \pm 0.5 \mathrm{ng} / \mathrm{L}$ for

areas of Tenerife were analysed. In these samples, DEP and DCHP were found at concentrations below their LOQ of the method $(0.63 \mu \mathrm{g} / \mathrm{kg} \mathrm{dw}$ and $0.14 \mu \mathrm{g} / \mathrm{kg} \mathrm{dw}$, respectively), while BBP was quantified at $5 \mu \mathrm{g} / \mathrm{kg} \mathrm{dw}$. DBP, for its part, was quantified between 9 and $52 \mu \mathrm{g} / \mathrm{kg} \mathrm{dw}$. It is noteworthy that the underground gallery runoff water sample (RW2) presented lower concentration levels of PAEs, compared to a rainwater runoff (RW3) from the same area. This fact can be explained because the rock that makes up the structure of the gallery can filter the surface water, thus improving its quality. All these runoff water samples, except the one stored in a plastic tank, are found in areas with high agricultural activity. Therefore, the high concentration at which some PAEs, such as DBP, have been found (1156.7 ng/L for RW3 and $938.1 \mathrm{ng} / \mathrm{L}$ for RW4) is not surprising. In addition, RW5 is the only runoff water sample in which DEHP has been quantified $(142.0 \mathrm{ng} / \mathrm{L})$ which can be attributed to the material of the container in which the sample was preserved. Taking into account that no works have been found in which rainwater runoff has been analysed, and that the evaluated runoff waters were mostly urban, the results obtained for these samples have been compared with those works in which rainwater samples were analysed. Teil et al. [47] evaluated the atmospheric fate of PAEs in an urban area in Paris (France), Fernández-Amado et al. [48] in sub-urban area of A Coruña (Spain), and Polyakova et al. [49] in rainwater samples from the southwest of Moscow (Russia), finding the presence of DEP, BBP, DBP, and DEHP at concentration values between 0.081 and $189 \mu \mathrm{g} / \mathrm{L}$. In general terms, the concentrations at which PAEs were presented in these samples are much higher

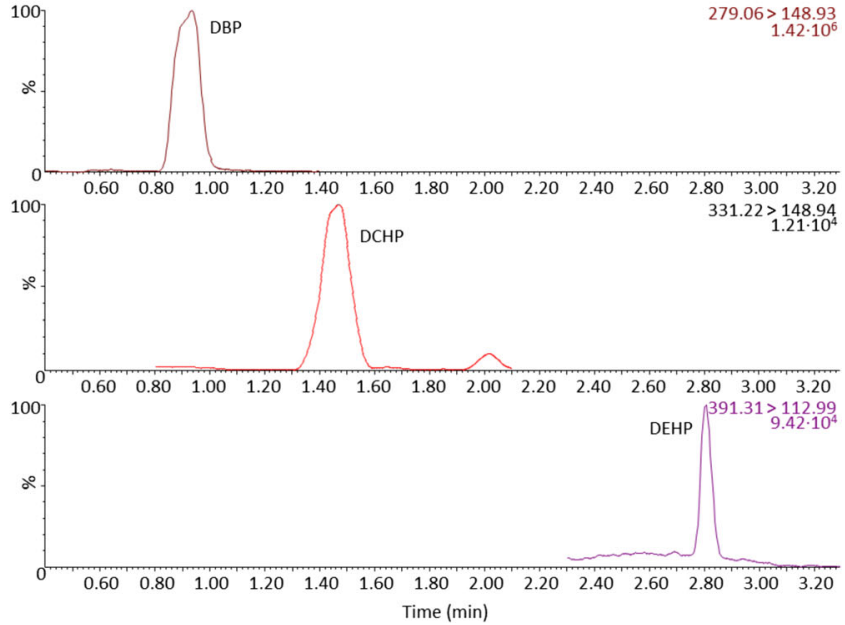

DPP, $116.1 \pm 0.4 \mathrm{ng} / \mathrm{L}$ for BBP, $1974.4 \pm 0.3 \mathrm{ng} / \mathrm{L}$ for DBP, $211.2 \pm$ $0.4 \mathrm{ng} / \mathrm{L}$ for DCHP, and lower than $0.074 \mathrm{ng} / \mathrm{L}$ for DEHP

than the ones found in this work $(0.105-1.157 \mu \mathrm{g} / \mathrm{L})$. The difference in concentrations with respect to the analysed runoff water samples is very clear, except for DBP, with an occurrence range $0.029-7.600 \mu \mathrm{g} / \mathrm{L}$ compared to $0.105-$ $1.157 \mu \mathrm{g} / \mathrm{L}$ in this study.

In general, the concentration values obtained for DEHP are well below the permissible limits established by the US EPA of $6.0 \mu \mathrm{g} / \mathrm{L}$ [8] and by the WHO of $8 \mu \mathrm{g} / \mathrm{L}$ [9] for drinking water. Likewise, in particular for wastewater samples, the quantified value is above the maximum annual average established by the European Union [4] on environmental quality standards in the field of water policy for priority substances $(1.3 \mu \mathrm{g} / \mathrm{L})$.

\section{Comparison with other methods}

The main aspects of the developed method performance were compared with those in which alternative solvents were employed for the extraction of plastic migrants from water matrices (Table 3). In this regard, the LOQ values obtained in the present work are much lower than those obtained in previous works in which the evaluation of PAEs and/or DEHA in water samples was carried out using DESs [50] or ILs [51-55]. Only the approaches developed by Mogaddam et al. [56] and Mirzajani et al. [57], in which polyethylene-packed injection solutions and mineral water were analysed, respectively, obtained LOQs in the same order. In the first case, $65 \mu \mathrm{L}$ of menthol:decanoic acid 1:2 HNADES was applied in a microwave (MWA) and air-assisted (AA)-LLME of $5 \mathrm{~mL}$ of sample solution prior to GC-MS for the determination of three PAEs 


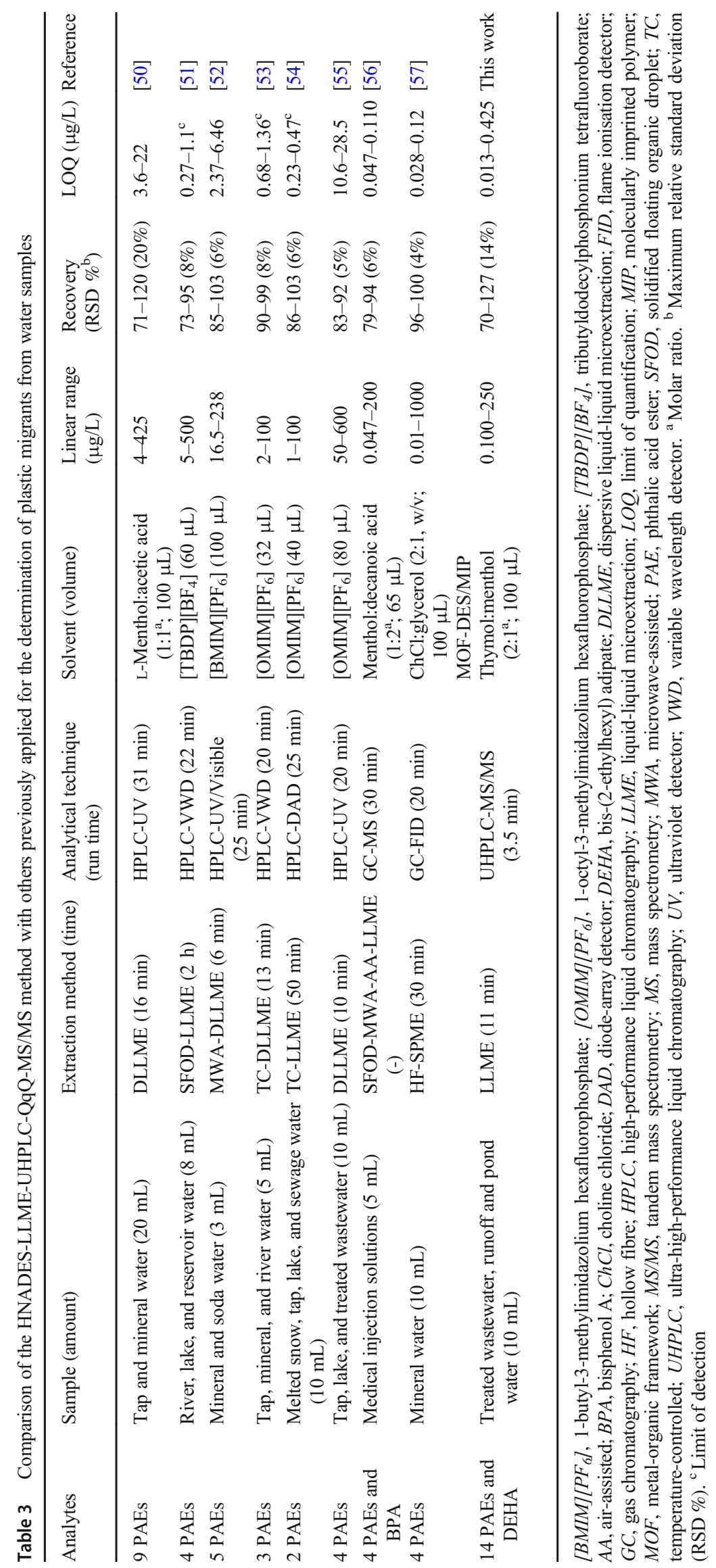


(DEP, DBP, DEHP), DEHA, and bisphenol A (BPA). In the second case, a hollow fibre (HF) and a monolithic fibre based on metal-organic framework (MOF) (UMCM-1)DES (choline chloride (ChCl):glycerol 2:1 (w/v))/molecularly imprinted polymers (MIPs), in which DES was used as substrate for MOFs, were employed for the extraction of four phthalates (DMP, DEP, DIBP, DBP), and determination by GC-flame-ionisation detector (FID). In addition, a reduced number of PAEs were evaluated in these previous studies highlighting not only the difficulty of coupling DES to chromatographic systems $[21,58]$ but also the limitations of the use of conventional detection systems such as diode-array detector (DAD), ultraviolet detector (UV), or FID with the characteristic chromatographic bands associated with DESs. Another important advantage of the developed method is the extraction time since only two works achieved a slightly lower extraction time but requiring additional assistance like microwave [52], cooling in an ice-bath [55], or as in the case of Zhang et el. [53], the control of temperature. In line with this, the analysis time employed is the shortest one, taking advantage of the combination of UHPLC with MS/MS which provides not only a selective and sensitive determination, but also a fast chromatographic performance.

Apart from that, an important aspect that need to be consider when novel and sustainable methodologies are proposed in the literature should be highlighted, especially for the evaluation of environmental samples due to the complexity of this kind of matrices. The use of adequate surrogates or instrumental internal standards that guarantee the reliability of the obtained data should be considered. In this sense, the use of isotopically deuterated compounds is preferred since the application of other PAEs, which although are not included into the target selected compounds, have been demonstrated to be in the evaluated samples [59-61] as occur in the works of Ortega-Zamora et al. [50] and Mogaddam et al. [56], which could pose serious doubts on the reliability of the obtained results. This practice is especially questionable when, in addition, the selected surrogates are also classified as toxic substances and priority pollutants with prevalence in the environment [3, 5-7].

This work constitutes a very simple method that does not entail any modification of the initial conditions of the samples, including $\mathrm{pH}$ or temperature, in contrast to others such as that of Ortega-Zamora et al. [50], Mogaddam et al. [56], or Mirzajani et al. [57]. Moreover, the high water stability of the thymol:menthol HNADES employed [18] in contrast to other DES previously applied for the evaluation of aqueous matrices has been demonstrated [50].

Finally, in economic terms, compared with other methodologies in which ILs or complex sorbents were prepared, the proposed extraction methodology highlights for its very inexpensive performance. With only $4.50 €, 100$ samples can be analysed (less than 5 euro cents per sample).

\section{Conclusions}

In this study, an analytical method based on a non-ionic HNADES (thymol:menthol) LLME procedure combined with UHPLC-QqQ-MS/MS for the evaluation of 14 PAEs and one adipate (DEHA) in water samples of environmental concern (treated wastewater, runoff water, and pond water) has been developed for the first time. The whole methodology was thoroughly validated in terms of matrix effect, linearity, extraction capacity, and sensitivity, with excellent results. Good linearity was obtained in all cases $\left(R^{2}\right.$ higher than 0.9954$)$, while recovery values were in the range $70-127 \%$ with RSDs lower than $14 \%$ in all studied matrices. LOQs of the method were found in the range $0.013-0.425 \mu \mathrm{g} / \mathrm{L}$ for all samples and analytes which demonstrated the good sensitivity of the procedure despite the need of diluting the final extract to assure the good performance of the UHPLC-QqQ-MS/MS analysis.

The combination of thymol:menthol as green extraction solvent together with UHPLC-MS/MS analysis allows the determination of organic contaminants of highly concern, such as PAEs or DEHA, at very low concentration levels in a single run. In this regard, an interesting and sustainable alternative extraction technique has been proposed and offers a smart, simple, fast, inexpensive, effective, and safe alternative. In addition, it allows the use of very low volumes of a biocompatible solvent to achieve excellent results in terms of extraction efficiency and sensitivity. Finally, the methodology was applied to the analysis of treated wastewater, runoff water, and pond water samples from Tenerife and Gran Canaria, finding the presence of DEP, DAP, DPP, BBP, DBP, DCHP, and DEHP in some on the evaluated matrices, in the range 105.2-3414 ng/L. The proposed method constitutes a good green approach that fulfils the main principles of Green Analytical Chemistry, for the analysis of highly concern compounds in aqueous environments.

Supplementary Information The online version contains supplementary material available at https://doi.org/10.1007/s00216-021-03166-1.

Acknowledgements Á. Santana-Mayor and R. Rodríguez-Ramos would like to thank the Canary Agency of Economy, Industry, Trade and Knowledge of the Government of the Canary Islands for the FPI fellowship (co-financed with an $85 \%$ from European Social Funds). B. SocasRodríguez would like to thank the Spanish Ministry of Science, Innovation and Universities for her "Juan de la Cierva" postdoctoral grant. Authors would like to acknowledge the use of the Research Support General Service (SEGAI) of the University of La Laguna.

Funding This work has been supported by the Spanish Ministry of Economy, Industry and Competitiveness (project AGL2017-89257-P).

\section{Compliance with ethical standards}

Conflict of interest The authors declare that they have no conflict of interest. 


\section{References}

1. Hermabessiere L, Dehaut A, Paul-Pont I, Lacroix C, Jezequel R, Soudant P, et al. Occurrence and effects of plastic additives on marine environments and organisms: a review. Chemosphere. 2017;182:781-93. https://doi.org/10.1016/j.chemosphere.2017. 05.096.

2. Net S, Delmont A, Sempéré R, Paluselli A, Ouddane B. Reliable quantification of phthalates in environmental matrices (air, water, sludge, sediment and soil): a review. Sci Total Environ. 2015;515516:162-80. https://doi.org/10.1016/j.scitotenv.2015.02.013.

3. European Union. Regulation (EC) No 1907/2006 of the European Parliament and of the Council of 18 December 2006 concerning the Registration, Evaluation, Authorisation and Restriction of Chemicals (REACH), establishing a European Chemicals Agency, amending Directive 1999/4. Official Journal of the European Union. https://eur-lex.europa.eu/legal-content/EN/ TXT/?uri=CELEX\%3A02006R1907-20200824. Accessed 15 Nov 2020.

4. European Union. Directive 2008/105/EC of the European Parliament and of the Council of 16 December 2008 on environmental quality standards in the field of water policy, amending and subsequently repealing Council Directives 82/176/EEC, 83/513/ EEC, 84/156/EEC, 84/491/EEC. Official Journal of the European Union. https://eur-lex.europa.eu/eli/dir/2008/105/2013-09-13. Accessed 15 Nov 2020.

5. US EPA. Final Scopes of the Risk Evaluations To Be Conducted for Twenty Chemical Substances Under the Toxic Substances Control Act. 2020. https://www.federalregister.gov/documents/ 2020/09/04/2020-19671/final-scopes-of-the-risk-evaluations-tobe-conducted-for-twenty-chemical-substances-under-the-toxic. Accessed 15 Nov 2020

6. US EPA. 40 CFR Appendix A to Part 423 - 126 Priority Pollutants. In: Code of Federal Regulations (annual edition). 2019. https:// www.govinfo.gov/app/details/CFR-2019-title40-vol31/CFR-2019title40-vol31-part423-appA. Accessed 15 Nov 2020.

7. US EPA. Phthalates Action Plan. 2012. https://www.epa.gov/ assessing-and-managing-chemicals-under-tsca/phthalates. Accessed 15 Nov 2020.

8. US EPA. 40 CFR 141 - National Primary Drinking Water Regulations: Maximum Contaminant Levels and Maximum Residual Disinfectant Levels. In: Code of Federal Regulations (annual edition). 2019. https://www.govinfo.gov/app/details/CFR2019-title40-vol25/CFR-2019-title40-vol25-part141. Accessed 15 Nov 2020.

9. WHO. Guidelines for drinking-water quality: fourth edition incorporating the first addendum. 2017. https://www.who.int/ publications/i/item/9789241549950. Accessed 15 Nov 2020.

10. Rezaee M, Yamini Y, Faraji M. Evolution of dispersive liquidliquid microextraction method. J Chromatogr A. 2010;1217: 2342-57. https://doi.org/10.1016/j.chroma.2009.11.088.

11. Płotka-Wasylka J, Rutkowska M, Owczarek K, Tobiszewski M, Namieśnik J. Extraction with environmentally friendly solvents. TrAC - Trends Anal Chem. 2017;91:12-25. https://doi.org/10. 1016/j.trac.2017.03.006.

12. Lee J, Jung D, Park K. Hydrophobic deep eutectic solvents for the extraction of organic and inorganic analytes from aqueous environments. TrAC - Trends Anal Chem. 2019;118:853-68. https://doi. org/10.1016/j.trac.2019.07.008.

13. European Union. Commission Decision of 12 August 2002 implementing Council Directive 96/23/EC concerning the performance of analytical methods and the interpretation of results (2002/657/EC). Off J Eur Union 2002. https://eur-lex.europa.eu/ legal-content/EN/TXT/?uri=CELEX\%3A02002D0657-20040110. Accessed 15 Nov 2020.
14. Santana-Mayor Á, Socas-Rodríguez B, Afonso M del M, Palenzuela-López JA, Rodríguez-Delgado MÁ. Reduced graphene oxide-coated magnetic-nanoparticles as sorbent for the determination of phthalates in environmental samples by micro-dispersive solid-phase extraction followed by ultra-high-performance liquid chromatography tandem mass spectrometry. J Chromatogr A. 2018;1565:36-47. https://doi.org/10.1016/j.chroma.2018.06.031.

15. FAO. Coping with water scarcity. An action framework for agriculture and food security. Food and Agriculture Organization of the United Nations. 2012. http://www.fao.org/3/a-i3015e.pdf. Accessed 15 Nov 2020.

16. Gobierno de Canarias. Recursos hídricos. In: El agua en Canarias. Consejería de Transición Ecológica, Lucha contra el Cambio Climático y Planificación Territorial. 2019. https://www. gobiernodecanarias.org/medioambiente/temas/calidad-del-agua/el agua_en_canarias/recursos_hidricos/\#centercontainer. Accessed $1 \overline{5}$ Nov 2020.

17. Gobierno de Canarias Plan de Regadíos de Canarias 2014-2020. In: Inversiones en Regadíos. Dirección General de Agricultura y Desarrollo Rural. 2014. https://www.gobiernodecanarias.org/ agricultura/docs/desarrollo-rural/regadio/PRC_avance.pdf. Accessed 15 Nov 2020.

18. Adeyemi I, Sulaiman R, Almazroui M, Al-Hammadi A, AlNashef IM. Removal of chlorophenols from aqueous media with hydrophobic deep eutectic solvents: experimental study and COSMO RS evaluation. J Mol Liq. 2020;311:113180. https://doi.org/10. 1016/j.molliq.2020.113180.

19. ECHA. Thymol. In: European Chemical Agency of the European Union. 2020. https://echa.europa.eu/es/registration-dossier/-/ registered-dossier/11030/1. Accessed 15 Nov 2020.

20. ECHA. Menthol. In: European Chemical Agency of the European Union. 2020. https://echa.europa.eu/es/registration-dossier/-/ registered-dossier/13758/1. Accessed 15 Nov 2020.

21. Makoś P, Słupek E, Gębicki J. Hydrophobic deep eutectic solvents in microextraction techniques-a review. Microchem J. 2020;152: 104384. https://doi.org/10.1016/j.microc.2019.104384.

22. Lu C, Cao J, Wang N, Su E. Significantly improving the solubility of non-steroidal anti-inflammatory drugs in deep eutectic solvents for potential non-aqueous liquid administration. Medchemcomm. 2016;7:955-9. https://doi.org/10.1039/c5md00551e.

23. Abranches DO, Martins MAR, Silva LP, Schaeffer N, Pinho SP, Coutinho JAP. Phenolic hydrogen bond donors in the formation of non-ionic deep eutectic solvents: the quest for type v des. Chem Commun. 2019;55:10253-6. https://doi.org/10.1039/c9cc04846d.

24. Aydin F, Yilmaz E, Soylak M. Vortex assisted deep eutectic solvent (DES)-emulsification liquid-liquid microextraction of trace curcumin in food and herbal tea samples. Food Chem. 2018;243: 442-7. https://doi.org/10.1016/j.foodchem.2017.09.154.

25. Faraji M. Determination of some red dyes in food samples using a hydrophobic deep eutectic solvent-based vortex assisted dispersive liquid-liquid microextraction coupled with high performance liquid chromatography. J Chromatogr A. 2019;1591:15-23. https://doi. org/10.1016/j.chroma.2019.01.022.

26. Sarafraz-Yazdi A, Amiri A. Liquid-phase microextraction. TrAC Trends Anal Chem. 2010;29:1-14. https://doi.org/10.1016/j.trac. 2009.10.003.

27. Yang J, Li Y, Wang Y, Ruan J, Zhang J, Sun C. Recent advances in analysis of phthalate esters in foods. TrAC - Trends Anal Chem. 2015;72:10-26. https://doi.org/10.1016/j.trac.2015.03.018.

28. Tran NH, Chen H, Van Do T, Reinhard M, Ngo HH, He Y, et al. Simultaneous analysis of multiple classes of antimicrobials in environmental water samples using SPE coupled with UHPLC-ESIMS/MS and isotope dilution. Talanta. 2016;159:163-73. https:// doi.org/10.1016/j.talanta.2016.06.006.

29. Iparraguirre A, Navarro P, Rodil R, Prieto A, Olivares M, Etxebarria N, et al. Matrix effect during the membrane-assisted 
solvent extraction coupled to liquid chromatography tandem mass spectrometry for the determination of a variety of endocrine disrupting compounds in wastewater. J Chromatogr A. 2014;1356:163-70. https://doi.org/10.1016/j.chroma.2014.06.051.

30. Matuszewski BK, Constanzer ML, Chavez-Eng CM. Strategies for the assessment of matrix effect in quantitative bioanalytical methods based on HPLC-MS/MS. Anal Chem. 2003;75:3019-30. https://doi.org/10.1021/ac020361s.

31. Rausch AK, Brockmeyer R, Schwerdtle T. Development and validation of a liquid chromatography tandem mass spectrometry multi-method for the determination of 41 free and modified mycotoxins in beer. Food Chem. 2021;338:127801. https://doi.org/10. 1016/j.foodchem.2020.127801.

32. Shin D, Kim J, Kang HS. Simultaneous determination of multipesticide residues in fish and shrimp using dispersive-solid phase extraction with liquid chromatography-tandem mass spectrometry. Food Control. 2021;120:107552. https://doi.org/10.1016/j. foodcont.2020.107552.

33. Richter LHJ, Jacobs CM, Mahfoud F, Kindermann I, Böhm M, Meyer MR. Development and application of a LC-HRMS/MS method for analyzing antihypertensive drugs in oral fluid for monitoring drug adherence. Anal Chim Acta. 2019;1070:69-79. https:// doi.org/10.1016/j.aca.2019.04.026.

34. Qiu J, Chen H, Ji Y, Li T, Li A. Evaluation of different strategies to minimize the matrix effects on LC-MS/MS analysis of multiple lipophilic shellfish toxins in both acidic and alkaline chromatographic conditions. Toxicon. 2020;188:16-26. https://doi.org/10. 1016/j.toxicon.2020.10.002.

35. Gao DW, Wen ZD. Phthalate esters in the environment: a critical review of their occurrence, biodegradation, and removal during wastewater treatment processes. Sci Total Environ. 2016;541: 986-1001. https://doi.org/10.1016/j.scitotenv.2015.09.148.

36. European Union. European Union Risk Assessment Report DIBUTYL PHTHALATE (DBP). Addendum to the Environmental Section - 2004. Institute for Health and Consumer Protection. European Chemicals Bureau. 1st Priority List. Vol. 29. 2004. https://echa.europa.eu/documents/10162/ba7f7c39-dab64dca-bc8e-dfab7ac53e37. Accessed 15 Nov 2020.

37. European Union. European Union Risk Assessment Report BIS(2ETHYLHEXYL) PHTHALATE (DEHP). Institute for Health and Consumer Protection. European Chemicals Bureau. 2nd Priority List. Vol. 80. 2008. https://publications.jrc.ec.europa.eu/ repository/bitstream/JRC45705/dehpreport042.pdf. Accessed 15 Nov 2020.

38. European Union. European Union Risk Assessment Report benzyl butyl phthalate (BBP). Institute for Health and Consumer Protection. European Chemicals Bureau. 3rd Priority List. Vol. 76. 2007. https://echa.europa.eu/documents/10162/bad5c92893a5-4592-a4f6-e02c5e89c299. Accessed 15 Nov 2020.

39. Gao D, Li Z, Wen Z, Ren N. Occurrence and fate of phthalate esters in full-scale domestic wastewater treatment plants and their impact on receiving waters along the Songhua River in China. Chemosphere. 2014;95:24-32. https://doi.org/10.1016/j. chemosphere.2013.08.009.

40. Clara M, Windhofer G, Hartl W, Braun K, Simon M, Gans O, et al. Occurrence of phthalates in surface runoff, untreated and treated wastewater and fate during wastewater treatment. Chemosphere. 2010;78:1078-84. https://doi.org/10.1016/j. chemosphere.2009.12.052.

41. Gani KM, Rajpal A, Kazmi AA. Contamination level of four priority phthalates in north Indian wastewater treatment plants and their fate in sequencing batch reactor systems. Environ Sci Process Impacts. 2016;18:406-16. https://doi.org/10.1039/ c5em00583c

42. Al-Saleh I, Elkhatib R, Al-Rajoudi T, Al-Qudaihi G. Assessing the concentration of phthalate esters (PAEs) and bisphenol A (BPA) and the genotoxic potential of treated wastewater (final effluent) in Saudi Arabia. Sci Total Environ. 2017;578:440-51. https://doi.org/ 10.1016/j.scitotenv.2016.10.207.

43. He J, Lv R, Zhan H, Wang H, Cheng J, Lu K, et al. Preparation and evaluation of molecularly imprinted solid-phase micro-extraction fibers for selective extraction of phthalates in an aqueous sample. Anal Chim Acta. 2010;674:53-8. https://doi.org/10.1016/j.aca. 2010.06.018.

44. Ye Q, Liu L, Chen Z, Hong L. Analysis of phthalate acid esters in environmental water by magnetic graphene solid phase extraction coupled with gas chromatography-mass spectrometry. J Chromatogr A. 2014;1329:24-9. https://doi.org/10.1016/j.chroma. 2013.12.086.

45. Wu H, Tian H, Chen MF, You JC, Du LM, Fu YL. Anionic surfactant micelle-mediated extraction coupled with dispersive magnetic microextraction for the determination of phthalate esters. J Agric Food Chem. 2014;62:7682-9. https://doi.org/10. 1021/jf502364x.

46. Rodríguez-Ramos R, Socas-Rodríguez B, Santana-Mayor Á, Rodríguez-Delgado MÁ. Nanomaterials as alternative dispersants for the multiresidue analysis of phthalates in soil samples using matrix solid phase dispersion prior to ultra-high performance liquid chromatography tandem mass spectrometry. Chemosphere. 2019;236:124377. https://doi.org/10.1016/j.chemosphere.2019. 124377.

47. Teil MJ, Blanchard M, Chevreuil M. Atmospheric fate of phthalate esters in an urban area (Paris-France). Sci Total Environ. 2006;354: 212-23. https://doi.org/10.1016/j.scitotenv.2004.12.083.

48. Fernández-Amado M, Prieto-Blanco MC, López-Mahía P, Muniategui-Lorenzo S, Prada-Rodríguez D. A comparative study of extractant and chromatographic phases for the rapid and sensitive determination of six phthalates in rainwater samples. Chemosphere. 2017;175:52-65. https://doi.org/10.1016/j. chemosphere.2017.02.001.

49. Polyakova OV, Artaev VB, Lebedev AT. Priority and emerging pollutants in the Moscow rain. Sci Total Environ. 2018;645: 1126-34. https://doi.org/10.1016/j.scitotenv.2018.07.215.

50. Ortega-Zamora C, González-Sálamo J, González-Sálamo J, Hernández-Sánchez C, Hernández-Sánchez C, Hernández-Borges $\mathrm{J}$, et al. Menthol-based deep eutectic solvent dispersive liquidliquid microextraction: a simple and quick approach for the analysis of phthalic acid esters from water and beverage samples. ACS Sustain Chem Eng. 2020;8:8783-94. https://doi.org/10.1021/ acssuschemeng.0c02603.

51. Hu L, Shan W, Zhang Y, Li S, Gao H, Lu R, et al. Liquid phase microextraction based on the solidification of a floating ionic liquid combined with high-performance liquid chromatography for the preconcentration of phthalate esters in environmental waters and in bottled beverages. RSC Adv. 2016;6:36223-30. https://doi.org/ 10.1039/c6ra00788k.

52. Wang R, Su P, Yang Y. Optimization of ionic liquid-based microwave-assisted dispersive liquid-liquid microextraction for the determination of plasticizers in water by response surface methodology. Anal Methods. 2013;5:1033-9. https://doi.org/10.1039/ c2ay26313k.

53. Zhang H, Chen X, Jiang X. Determination of phthalate esters in water samples by ionic liquid cold-induced aggregation dispersive liquid-liquid microextraction coupled with high-performance liquid chromatography. Anal Chim Acta. 2011;689:137-42. https://doi. org/10.1016/j.aca.2011.01.024.

54. Zhou Q, Zhang X, Xie G. Simultaneous analysis of phthalate esters and pyrethroid insecticides in water samples by temperaturecontrolled ionic liquid dispersive liquid-phase microextraction combined with high-performance liquid chromatography. Anal Methods. 2011;3:1815-20. https://doi.org/10.1039/c1ay05137g. 
55. Sha C, Yi-Sheng Z, Shui-Yuan C, Tian Q, Hao S. Development of an ionic liquid-based dispersive liquid-liquid micro-extraction method for the determination of phthalate esters in water samples. J Sep Sci. 2011;34:1503-7. https://doi.org/10.1002/jssc. 201000855.

56. Mogaddam MRA, Mohebbi A, Farajzadeh MA, Nemati M. Endocrine-disrupting compounds surveying in polyethylene packed injection solutions using microwave-accelerated airassisted liquid-liquid microextraction based on solidification of deep eutectic solvent. Sep Sci Technol. 2020. https://doi.org/10. 1080/01496395.2020.1788594.

57. Mirzajani R, Kardani F, Ramezani Z. Fabrication of UMCM-1 based monolithic and hollow fiber - metal-organic framework deep eutectic solvents/molecularly imprinted polymers and their use in solid phase microextraction of phthalate esters in yogurt, water and edible oil by GC-FID. Food Chem. 2020;314:126179. https://doi. org/10.1016/j.foodchem.2020.126179.

58. Cai T, Qiu H. Application of deep eutectic solvents in chromatography: a review. TrAC - Trends Anal Chem. 2019;120:115623. https://doi.org/10.1016/j.trac.2019.115623.
59. Manzo V, Becerra-Herrera M, Arismendi D, Molina-Balmaceda A, Caraballo MA, Richter P. Rotating-disk sorptive extraction coupled to gas chromatography mass spectrometry for the determination of phthalates in bottled water. Anal Methods. 2019;11:6111-8. https:// doi.org/10.1039/c9ay02076d.

60. Farahani A, Ramezani M, Hassan J, Niazi A. In tube ultrasonic and air assisted liquid-liquid microextraction-gas chromatography-mass spectrometry determination: a novel method for the determination of phthalate esters in aqueous samples. J Braz Chem Soc. 2017;28: 967-74. https://doi.org/10.21577/0103-5053.20160247.

61. Al-Saleh I, Elkhatib R. Analysis of phthalates residues in apple juices produced in Saudi Arabia. J Food Meas Charact. 2014;8: 373-80. https://doi.org/10.1007/s11694-014-9202-7.

Publisher's note Springer Nature remains neutral with regard to jurisdictional claims in published maps and institutional affiliations. 